\title{
Improving the diagnosis of X-linked hypophosphatemia: recommendations to optimize diagnostic flow and clinician/geneticist cooperation in the Italian clinical practice
}

\author{
Emanuele Agolini ${ }^{1}$, Roberto Chimenz ${ }^{2}$, Danilo Fintini ${ }^{3}$, Vito Guarnieri ${ }^{4}$, Laura Guazzarotti ${ }^{5}$, Stefano Mora ${ }^{6}$, Leonardo Salviati ${ }^{7}$, \\ Giovanna Weber ${ }^{8}$ \\ ${ }^{1}$ Medical Genetics Laboratory, IRCCS Ospedale Pediatrico Bambino Gesù, Rome - Italy \\ ${ }^{2}$ Pediatric Nephrology Unit, Azienda Ospedaliera Universitaria G. Martino, Messina - Italy \\ ${ }^{3}$ Endocrinology Unit, University Pediatric Hospital Department, IRCCS Ospedale Pediatrico Bambino Gesù, Rome - Italy \\ ${ }^{4}$ Medical Genetics Division, Fondazione IRCCS Casa Sollievo della Sofferenza di San Giovanni Rotondo, Foggia - Italy \\ ${ }^{5}$ Clinical Pediatric Unit, Azienda Ospedaliera Universitaria di Padova, Padua - Italy \\ ${ }^{6}$ Pediatric Endocrinology Unit, IRCCS Ospedale San Raffaele, Milan - Italy \\ ${ }^{7}$ Clinical Genetics Unit, Department of Women and Children's Health, University of Padova, Padua - Italy \\ ${ }^{8}$ Vita-Salute San Raffaele University, Department of Pediatrics, IRCCS Ospedale San Raffaele, Milan - Italy
}

\begin{abstract}
Objective: To provide Italian expert opinion-based practical recommendations to improve the cooperation between clinicians and geneticists in order to optimize diagnostic flow and care of X-linked hypophosphatemia (XLH).

Methods: A panel of four geneticists and four clinicians from Italian reference centers for the diagnosis and management of XLH met virtually, first to highlight the critical issues in patient care and then to identify and share proposals to improve the diagnostic and care path of XLH.

Results: Critical issues emerged regarding the transfer of adequate clinical information from clinicians to geneticists, standardization and clarity of genetic reporting, and adequate interactions between clinicians and geneticists during patients' follow-up. The necessary requirements for an appropriate request for evaluation of genetic variants and the need for a clear and clinically useful genetic report were agreed upon. Specifically designed template forms to be adopted with appropriate adjustments were defined and are here proposed for both the clinician's request and the geneticist's report.

Conclusions: The expert group strongly believes that collaboration between clinicians and geneticists should be encouraged in XLH, not only in the diagnostic phase but also during a patient's follow-up, in order to manage patients more comprehensively and effectively.
\end{abstract}

Keywords: Genetic testing, Hypophosphatemic rickets, Patient care, PHEX, X-linked hypophosphatemia, XLH diagnosis

\section{Introduction}

X-linked hypophosphatemia $(\mathrm{XLH})$ is a rare, progressive phosphate wasting disorder, genetically transmitted as a dominant trait and caused by inactivating mutations of the PHEX (Phosphate Regulating Gene with Homologies to Endopeptidases on the $X$ chromosome) gene, which is located in the Xp22.1-22.2

Received: January 22, 2021

Accepted: March 24, 2021

Published online: April 19, 2021

Corresponding author

Roberto Chimenz

U.O. di Nefrologia Pediatrica con Dialisi

A.O.U. G. Martino

Via Consolare Valeria 1

98123 Messina - Italy

rchimenz@unime.it locus of the $X$ chromosome (1). The PHEX gene encodes for a transmembrane endopeptidase, a protein-cleavage enzyme that is mainly expressed in osteoblasts, osteocytes, and odontoblasts (2-5). Pathogenic variants of the PHEX gene result in a loss of function of the corresponding namesake protein, which, in turn, causes an increase in circulating fibroblast growth factor 23 (FGF23) concentration, though the mechanism linking PHEX and FGF23 has not yet been fully clarified (6). XLH is the most common cause of inherited phosphate wasting disorders and the most common form of inherited rickets, with an incidence of $1 / 20,000$ (7-9). The clinical spectrum ranges from isolated hypophosphatemia to osteo- and odontomalacia, lower limb deformities, rickets, and disproportionate short stature, usually becoming evident during the first or second year of life. However, in some cases, the condition may not be manifest until adulthood, having sometimes been previously misdiagnosed as short stature (10-12). In XLH, early diagnosis followed by immediate treatment has a strong impact on the patient's 
long-term outcome; however, the diagnosis of this rare condition is often delayed (13).

The diagnosis of XLH is based on the combination of clinical, radiological, and biochemical findings. Hypophosphatemia due to renal phosphate wasting, increased alkaline phosphatase (ALP) activity, and elevated intact FGF23 concentration are the biochemical characteristics of XLH. However, FGF23 concentration is also influenced by other factors, in particular, phosphate intake and vitamin D therapy, and a normal concentration of FGF23 does not exclude XLH $(14,15)$. Confirmation of the clinical diagnosis of XLH by genetic analysis of the PHEX gene, with identification of a hemizygous (in males) or heterozygous (in females) pathogenic variant, is recommended in children and adults whenever feasible, as mentioned in Haffner et al. (European Consensus grade B, moderate recommendation) (14). The molecular genetic confirmation of the clinically and biochemically based diagnosis of XLH has been recommended as differentiation from other forms of hypophosphatemic rickets ( $\mathrm{HR}$ ), as there is a high overlap between $\mathrm{XLH}$ and other forms of HR both in clinical as well as in laboratory findings $(13,14)$. If genetic analysis is not available, elevated plasma levels of intact FGF23 and/or a positive family history for XLH can support the diagnosis (14). PHEX mutations have been found in $87 \%$ of familial cases but also in $72 \%$ of sporadic cases (16). For this reason, first-generation family members of a patient affected by the disease should be investigated, but in patients with a negative family history, it is recommended that genetic analysis of the PHEX gene is performed for confirmation $(8,17,18)$. The latest clinical practice guidelines for the diagnosis and management of XLH recommend offering genetic counseling to patients affected by the disease, which can also enable the screening of at-risk relatives (14).

Different techniques are available for the genetic diagnosis of $\mathrm{XLH}(12,13)$. All approaches require proper medical governance for the control of "red flags," such as obtainment of signed informed consent, compliance with the declared reporting timings, management of emergencies, clarity and reproducibility of the analytical result and of its interpretation, as well as possible reevaluation of the result itself. Effective interaction and cooperation between clinicians and geneticists are crucial to improving the diagnostic process of $\mathrm{XLH}$, starting when the patient's sample is first sent to the medical genetics laboratory.

Until recently, treatment of XLH was limited to the administration of phosphate and activated vitamin $D$ to try to address the chronic hypophosphatemia. This therapy is associated with variable improvement in the clinical features of $\mathrm{XLH}$ and is complicated by adverse events, including nephrocalcinosis and hyperparathyroidism (20). Over the past two decades, research into the pathogenesis of XLH has identified novel potential treatment targets. Since 2019, a fully human monoclonal antibody that specifically targets FGF23 acting on the pathogenetic mechanism of the disease is available in Italy for the treatment of $\operatorname{XLH}(19,20)$. The availability of this therapeutic innovation makes it even more important to be able to identify patients as early as possible, to promptly implement the appropriate treatment, and prevent the disease from evolving and degenerating in later stages of life.

This Italian expert opinion paper aims to provide practical recommendations to foster the communication and collaboration between clinicians and geneticists in order to optimize the diagnostic flow and the care of patients with $\mathrm{XLH}$.

\section{Methods}

In June 2020, a group of experts met virtually via the web to discuss the opportunity of producing recommendations aimed at facilitating and making more effective the communication and cooperation between geneticists and clinicians in order to improve the diagnostic flow of XLH and the care pathway of XLH patients. The group comprised a panel of four geneticists and four clinicians (the experts) from National reference centers for the diagnosis and management of XLH (third-level centers), located in different Italian geographical areas (i.e., North West, North East, Center, and South). A brief preliminary survey completed by the panel of experts had identified some failings in the following aspects:

- adequate clinical information about the patients accompanying the request for genetic analysis;

- standardization and clarity of genetic reporting;

- interaction between clinicians and geneticists following genetic diagnosis and patients' follow-up.

These open issues confirmed the need for standardized protocols to be shared between clinicians and geneticists. According to the personal experience of the experts involved, the diagnostic and management processes were reviewed and discussed, and practical recommendations were issued as proposed hereafter.

\section{Discussion and results}

\section{Request for evaluation of genetic variants in a patient with suspected HR}

Results from the survey underlined that, while the clinicians seemed to be confident that their requests for genetic analysis were accompanied with adequate clinical information, either following established hospital protocols or at their personal discretion, half of the geneticists complained that this is not always the case. In particular, requests coming from external first- or second-level centers often lack sufficient anamnestic data and clinical information to support the geneticist in better understanding and contextualizing the request itself. Clinicians and geneticists agreed that the request for evaluation of genetic variants in a patient with suspected XLH should meet the following requirements:

- be submitted by means of specific forms;

- include clinical and family history;

- include phenotypic details supporting the diagnostic suspicion;

- when possible, biological samples from parents or other affected family members should be made available at the same time.

Geneticists confirmed that having clinical information at the time of the request is crucial for them, although they acknowledged that it is not easy to have one single form 
suitable for all requests, because each condition has its own specificities, especially in the context of rare diseases such as XLH. In any case, the agreed recommendation is to implement and use quite simple forms reporting essential information that can be easily and rapidly completed. A proposal of a specifically designed template form that could be adopted with appropriate adjustments is shown in Table I.

TABLE I - Sample form for the request for assessment of genetic variants in patients with suspected hypophosphatemic rickets

\begin{tabular}{|c|c|c|c|}
\hline \multicolumn{4}{|c|}{ SEX ... DATE OF BIRTH } \\
\hline \multicolumn{4}{|c|}{ PHYSICAL EXAMINATION } \\
\hline & & YES & NO \\
\hline \multicolumn{4}{|l|}{ SHORT STATURE } \\
\hline \multicolumn{4}{|l|}{ CRANIAL ANOMALIES } \\
\hline \multicolumn{4}{|l|}{ DENTAL ABSCESSES } \\
\hline \multicolumn{4}{|l|}{ BONE DEFORMITY } \\
\hline \multicolumn{4}{|c|}{ ARTICULAR/BONE PAINS } \\
\hline \multicolumn{4}{|l|}{ MUSCLE WEAKNESS } \\
\hline \multicolumn{4}{|c|}{ LABORATORY INVESTIGATIONS } \\
\hline & NORMAL & INCREASED & DECREASED \\
\hline \multicolumn{4}{|l|}{ Serum ALP } \\
\hline \multicolumn{4}{|l|}{ Serum Ca } \\
\hline \multicolumn{4}{|l|}{ Serum Phosphate } \\
\hline \multicolumn{4}{|l|}{ Serum iPTH } \\
\hline \multicolumn{4}{|l|}{ Serum $1,25(\mathrm{OH})_{2} \mathrm{D}$} \\
\hline \multicolumn{4}{|l|}{ Serum 25(OH) D } \\
\hline \multicolumn{4}{|l|}{ Ca/Creatinine $(U)$} \\
\hline \multicolumn{4}{|l|}{$\mathrm{TmPO}_{4} / \mathrm{GFR}$} \\
\hline \multicolumn{4}{|l|}{ FGF23* } \\
\hline \multicolumn{4}{|c|}{ RADIOLOGICAL INVESTIGATIONS } \\
\hline & NORMAL & \multicolumn{2}{|c|}{ PATHOLOGICAL } \\
\hline \multicolumn{4}{|l|}{ RX FEMUR/TIBIA } \\
\hline \multicolumn{4}{|l|}{ RX WRIST and HAND } \\
\hline \multicolumn{4}{|c|}{ FAMILY HISTORY } \\
\hline & NORMAL & \multicolumn{2}{|c|}{ AFFECTED } \\
\hline \multicolumn{4}{|l|}{ FATHER } \\
\hline \multicolumn{4}{|l|}{ MOTHER } \\
\hline \multicolumn{4}{|l|}{ RELATIVE 1} \\
\hline \multicolumn{4}{|l|}{ RELATIVE 2} \\
\hline \multicolumn{4}{|l|}{ RELATIVE 3} \\
\hline Additional notes: & & & \\
\hline
\end{tabular}

*Specify if intact or C-terminal (i-FGF23 or c-FGF23) assay used and laboratory reference ranges.

ALP = alkaline phosphatase; FGF23 = fibroblast growth factor 23; GFR = glomerular filtration rate; iPTH = intact parathyroid hormone.

\section{Genetic analysis report}

Another aspect highlighted in the survey results and discussed in depth during the virtual meeting was that clinicians strongly need complete and clear information within the genetic analysis report, in particular for those centers where no genetic counseling service is available, to support the interaction and feedback to the patient and their family. It also has to be considered that the genetic outcome might not necessarily be positive or negative since variants of uncertain significance (VUS) might emerge. In such cases, the analysis is not conclusive and a family mapping exercise could be informative to help in the final definition of the eventual pathogenicity/benignity of the VUS. In this case, the genetic diagnosis would not end with the first report, thus prolonging the diagnostic process. Finally, an initial negative genetic result does not necessarily exclude the diagnostic hypothesis and it might be worth repeating the analysis after a few months, in case new techniques, evaluation panels, and scientific evidence have emerged.

Based on these premises, clinicians and geneticists discussed what information the genetic report should contain to facilitate its interpretation. Summarizing the respective clinicians' and geneticists' views, it was agreed that genetic reports should meet the following criteria:

- contain clear and easily interpretable information, correlated with the specified clinical picture;

- describe the pathogenetic variant with appropriate scientific references;

- include sensitivity, specificity, and reliability of the method used;

- follow the American College of Medical Genetics classification (21);

- provide a recommendation on the advisability of a posttest genetic visit, further genetic evaluations for the patient and/or his/her relatives, and genetic counseling.

The proposed example of a comprehensive form for genetic reporting is shown in Table II.

Upon receipt of the first genetic reporting, the expert panel suggestion is that the clinician:

- recheck the "specificity" of the diagnosis;

- consider the extension of the study in "key" family members;

- consider formal maternity/paternal verification (however, it has to be carefully considered that this test may have major ethical and juridical implications);

- consider the study of the inactivation of the $\mathrm{X}$ chromosome (X-linked diseases).

In the case of a negative outcome, level II investigations analysis, such as genomic array and Multiplex Ligation Probe Amplification or MLPA (the latter only in females) should be requested. Clinical exome as level II investigation analysis should only be requested if suspecting a condition other than $\mathrm{XLH}$ rickets.

\section{Genetic counseling}

Genetic counseling is the process of providing individuals and families with information on the nature, inheritance, 
TABLE II - Sample form for a genetic analysis report

\begin{tabular}{|c|}
\hline $\begin{array}{l}\text { Type of molecular analysis (NGS, Sanger, MLPA for the PHEX, } \\
\text { COL1A1, etc.) }\end{array}$ \\
\hline Univocal Patient/Analysis Identification Code \\
\hline Personal details of the proband and of the applicant \\
\hline $\begin{array}{l}\text { Proband: surname and name, DOB, place of birth, tax code, } \\
\text { residence (full address and telephone) }\end{array}$ \\
\hline Personal details of the applicant \\
\hline $\begin{array}{l}\text { Physician who requested the analysis (full address, telephone, } \\
\text { e-mail) }\end{array}$ \\
\hline Clinical indication for the analysis (bone fragility, rickets, etc.) \\
\hline $\begin{array}{l}\text { Source of biological material (blood, DNA, buccal brush, tissue } \\
\text { biopsy, etc.) }\end{array}$ \\
\hline Results, interpretation, and comments \\
\hline $\begin{array}{l}\text { For negative results (i.e., absence of pathogenic coding } \\
\text { mutations/presence of benign variants): }\end{array}$ \\
\hline $\begin{array}{l}\text { Suggest a clinical reevaluation and in case of confirm, to address } \\
\text { toward different analyses (i.e., MLPA) }\end{array}$ \\
\hline For positive results: \\
\hline $\begin{array}{l}\text { Name of mutated gene, exon, nomenclature of the variant at } \\
\text { DNA and protein level }\end{array}$ \\
\hline Inheritance (heterozygosity/homozygosity) \\
\hline $\begin{array}{l}\text { Variant classification (as for ACMG guidelines: VUS, likely } \\
\text { pathogenic, pathogenic) }\end{array}$ \\
\hline $\begin{array}{l}\text { Segregation pattern among the relatives, where available (de } \\
\text { novo, paternal, maternal, unknown) }\end{array}$ \\
\hline $\begin{array}{l}\text { Conclusion: description of the finding with the level of } \\
\text { pathogenicity/benignity, defined following the ACMG }\end{array}$ \\
\hline Comments 1: list of ACMGC criteria used to classify the variant \\
\hline $\begin{array}{l}\text { Comments 2: description of the pipeline of interpretation criteria } \\
\text { established for a given specific laboratory }\end{array}$ \\
\hline Methods \\
\hline $\begin{array}{l}\text { In case of a NGS multigenic panel: list of the genes within the } \\
\text { panel with their NM }\end{array}$ \\
\hline Sensibility and sensitivity of the genetic test \\
\hline $\begin{array}{l}\text { Description of the methodology applied (NGS platform, } \\
\text { molecular biology kits, equipment) }\end{array}$ \\
\hline $\begin{array}{l}\text { Limits of the genetic test (usually NGS does not identify exon } \\
\text { deletion/duplication nor mosaicism) }\end{array}$ \\
\hline $\begin{array}{l}\text { References (either for the methods applied and the results } \\
\text { interpretation) }\end{array}$ \\
\hline Signature and issue date \\
\hline
\end{tabular}

ACMG = American College of Medical Genetics; ACMGC = ACMG Classification; COL1A1 = collagen type I alpha-1 chain; $\mathrm{DOB}=$ date of birth; $\mathrm{MLPA}=$ multiplex ligation-dependent probe amplification; NGS = nextgeneration sequencing; NM = neutrophil migration; VUS = variants of uncertain significance.

and implications of genetic disorders to help them make informed medical and personal decisions (12). The growth of the profession of genetic counseling is progressing in parallel with the professional development of individual genetic counselors, which in Italy is, unfortunately, slower than it should be. The experts hope that the next decade will see an increase in educational paths and opportunities for professional advancement. Currently, third-level centers have a genetic counseling service, but this is not often the case in first- and second-level ones. The experts' recommendation is to have the genetic report delivered to the patient through a dedicated genetic counseling service, as also suggested in the recent European recommendations by Haffner et al. (14). However, acknowledging that a genetic counseling service is not always available, the experts recommend that, in the absence of a genetic counselor, the response to the patient should be given by the clinician. The possibility of referring the patient to external genetic counseling centers should also be considered.

\section{Follow-up after genetic reporting}

Within the results of the preliminary survey, it emerged that about $50 \%$ of the geneticists involved in the expert panel complained that they do not receive feedback from the clinicians regarding their genetic examination, especially when the request comes from external centers. During the virtual meeting discussion on this point, geneticists stressed that they believe that clinician's feedback could be extremely useful for the patient's subsequent follow-up. First, the genetic report may not end with the first result, because a family segregation study may be necessary. Second, the genetic analysis could be negative, disconfirming the clinician's diagnostic hypothesis. However, the negative result of the genetic test does not rule out the clinical hypothesis, since the phenotype remains fundamental, and direct confrontation is mandatory. In these cases, the geneticist's opinion on how to proceed and on the need to investigate first-generation family members is of major importance. Geneticists also claimed the usefulness of sharing outcome-related information with clinicians, even before reporting. For all of these reasons, it was agreed that collaboration is extremely helpful to plan an appropriate follow-up.

\section{Conclusions}

$\mathrm{XLH}$ is the most common form of hereditary rickets. However, clinicians, geneticists, and patients complain of the paucity of information and specific guidelines, which may lead to misdiagnosis and inappropriate management (11). The latest clinical practice guidelines (14) provided helpful recommendations for the management of the condition and recognized that "whenever possible, the diagnosis should be confirmed by molecular genetic analysis," also given that the diagnostic reliability of the FGF23 assays available in Italy is not fully reliable. A panel of clinicians and geneticists working in reference centers and experts in the diagnosis of rare inherited diseases, such as XLH, met in June 2020 to discuss the best flow to guide genetic confirmation of diagnosis and suggest recommendations to be followed. As an output of the discussion, experts strongly believe that collaboration between clinicians and geneticists should be encouraged, not only in the diagnostic phase but also during the patient's follow-up, to be able to manage patients more comprehensively and effectively. With the aim of favoring such cooperation, these brief 
practical recommendations have been produced, accompanied by templates of forms (suggestions to be adapted as appropriate) in order to helpfully provide clearer and more understandable requests and reports to ultimately optimize the diagnostic flow and management of patients with XLH.

\section{Acknowledgments}

We thank Renata Perego, an independent medical writer, for providing editorial support on behalf of Health Publishing \& Services Srl. This assistance was funded by Kyowa Kirin Srl.

\section{Disclosures}

Conflict of interest: The authors have no conflicts of interest to declare.

Financial support: Financial support for the preparation and publication of the article was provided by Kyowa Kirin Srl.

\section{References}

1. Francis F, Strom TM, Hennig S, et al. Genomic organization of the human PEX gene mutated in X-linked dominant hypophosphatemic rickets. Genome Res. 1997;7(6):573-585. CrossRef PubMed

2. Lipman ML, Panda D, Bennett HP, et al. Cloning of human PEX cDNA. Expression, subcellular localization, and endopeptidase activity. J Biol Chem. 1998;273(22):13729-13737. CrossRef PubMed

3. Sabbagh Y, Boileau G, Campos M, Carmona AK, Tenenhouse HS. Structure and function of disease-causing missense mutations in the PHEX gene. J Clin Endocrinol Metab. 2003;88(5):22132222. CrossRef PubMed

4. Beck L, Soumounou Y, Martel J, et al. Pex/PEX tissue distribution and evidence for a deletion in the $3^{\prime}$ region of the Pex gene in X-linked hypophosphatemic mice. J Clin Invest. 1997;99(6):1200-1209. CrossRef PubMed

5. Ruchon AF, Tenenhouse HS, Marcinkiewicz M, et al. Developmental expression and tissue distribution of Phex protein: effect of the Hyp mutation and relationship to bone markers. J Bone Miner Res. 2000;15(8):1440-1450. CrossRef PubMed

6. Beck-Nielsen SS, Mughal Z, Haffner D, et al. FGF23 and its role in X-linked hypophosphatemia-related morbidity. Orphanet J Rare Dis. 2019;14(1):58. CrossRef PubMed

7. Beck-Nielsen SS, Brock-Jacobsen B, Gram J, Brixen K, Jensen TK. Incidence and prevalence of nutritional and hereditary rickets in southern Denmark. Eur J Endocrinol. 2009;160(3):491-497. CrossRef PubMed

8. Beck-Nielsen SS, Brixen K, Gram J, Brusgaard K. Mutational analysis of PHEX, FGF23, DMP1, SLC34A3 and CLCN5 in patients with hypophosphatemic rickets. J Hum Genet. 2012;57(7): 453-458. CrossRef PubMed
9. Rafaelsen S, Johansson S, Ræder H, Bjerknes R. Hereditary hypophosphatemia in Norway: a retrospective population-based study of genotypes, phenotypes, and treatment complications. Eur J Endocrinol. 2016;174(2):125-136. CrossRef PubMed

10. Feng JQ, Clinkenbeard EL, Yuan B, White KE, Drezner MK. Osteocyte regulation of phosphate homeostasis and bone mineralization underlies the pathophysiology of the heritable disorders of rickets and osteomalacia. Bone. 2013;54(2): 213-221. CrossRef PubMed

11. Carpenter TO, Imel EA, Holm IA, Jan de Beur SM, Insogna KL. A clinician's guide to X-linked hypophosphatemia. J Bone Miner Res. 2011;26(7):1381-1388. CrossRef PubMed

12. Ruppe MD. X-linked hypophosphatemia. In: Adam MP, Ardinger $\mathrm{HH}$, Pagon RA, et al, eds. GeneReviews ${ }^{\circ}$. [Internet] Seattle, WA: University of Washington, Seattle; 2012 Feb 9:1993-2020. [updated 2017 Apr 13]

13. Thiele S, Werner R, Stubbe A, Hiort O, Hoeppner W. Validation of a next-generation sequencing (NGS) panel to improve the diagnosis of $\mathrm{X}$-linked hypophosphataemia $(\mathrm{XLH})$ and other genetic disorders of renal phosphate wasting. Eur J Endocrinol. 2020;183(5):497-504. CrossRef PubMed

14. Haffner D, Emma F, Eastwood DM, et al. Clinical practice recommendations for the diagnosis and management of X-linked hypophosphataemia. Nat Rev Nephrol. 2019;15(7): 435-455. CrossRef PubMed

15. Endo I, Fukumoto S, Ozono K, et al. Clinical usefulness of measurement of fibroblast growth factor 23 (FGF23) in hypophosphatemic patients: proposal of diagnostic criteria using FGF23 measurement. Bone. 2008;42(6):1235-1239. CrossRef PubMed

16. Gaucher C, Walrant-Debray O, Nguyen TM, Esterle L, Garabédian M, Jehan F. PHEX analysis in 118 pedigrees reveals new genetic clues in hypophosphatemic rickets. Hum Genet. 2009;125(4):401-411. CrossRef PubMed

17. Ruppe MD, Brosnan PG, Au KS, Tran PX, Dominguez BW, Northrup H. Mutational analysis of PHEX, FGF23 and DMP1 in a cohort of patients with hypophosphatemic rickets. Clin Endocrinol (Oxf). 2011;74(3):312-318. CrossRef PubMed

18. Morey M, Castro-Feijóo L, Barreiro J, et al. Genetic diagnosis of X-linked dominant hypophosphatemic rickets in a cohort study: tubular reabsorption of phosphate and 1,25(OH)2D serum levels are associated with PHEX mutation type. BMC Med Genet. 2011;12(1):116. CrossRef PubMed

19. Carpenter TO, Whyte MP, Imel EA, et al. Burosumab therapy in children with X-linked hypophosphatemia. N Engl J Med. 2018;378(21):1987-1998. CrossRef PubMed

20. Imel EA, White KE. Pharmacological management of X-linked hypophosphataemia. $\mathrm{Br} J$ Clin Pharmacol. 2019;85(6): 1188-1198. CrossRef PubMed

21. Kearney HM, Thorland EC, Brown KK, Quintero-Rivera F, South ST; Working Group of the American College of Medical Genetics Laboratory Quality Assurance Committee. American College of Medical Genetics standards and guidelines for interpretation and reporting of postnatal constitutional copy number variants. Genet Med. 2011;13(7):680-685. CrossRef PubMed 